\title{
EDITORIAL
}

\section{Understanding coupled human and natural systems in a changing world}

\author{
Zhifeng YANG (ه), Shikui DONG \\ State Key Laboratory of Water Environmental Simulation, School of Environment, Beijing Normal University, Beijing 100875, China
}

(C) Higher Education Press and Springer-Verlag Berlin Heidelberg 2010

It is now widely accepted that global change and human disturbances, such as global warming, economic globalization, population growth, and government policy changes are putting great pressures on the ecoenvironment worldwide. The impacts of land degradation, soil erosion, air and water pollution, biodiversity loss, and increased greenhouse gas emissions are damaging our living planet. This is challenging scientists and practitioners worldwide to think about the future sustainability of the global eco-environment. Academe, nongovernmental organizations, and government agencies have acknowledged that the environmental problems facing these complex systems involve understanding tightly coupled interrelationships between natural systems and human society. Furthermore, we now recognize that these problems cannot be addressed solely through technical innovations, political reformations, or economic development. Sound policy formulations and management decisions about the environment and natural resources necessitate effective collaborations among social and bio/ physical scientists and management practitioners, as well as a better understanding of the influence of differing scales of biological organization. The newly developed portfolios of coupled human-natural systems provide important insights into diverse complex systems that cannot be well-understood or effectively managed within a single dimension.

Coupled human-natural systems are integrated systems where people interact closely with the natural world. The U.S. National Science Foundation in establishing its Dynamics of Coupled Natural and Human Systems Program in 2001 recognized the need for enhancing our understanding of complex systems. This program was established to promote and financially support "quantitative, interdisciplinary analyses of relevant human and natural system processes and complex interactions among human and natural systems at diverse scales." As a result, there are major changes in progress concerning how the U.S. scientific community develops approaches to addressing interdisciplinary and applied eco-environmental problems. An increasing number of interdisciplinary programs have been integrating ecological and social sciences to study and better understand the dynamics of coupled human and natural systems. From this context, Beijing Normal University and Cornell University co-organized "International Workshop in Conservation and Sustainable Development: Understanding Coupled Socio-Cultural and Natural Systems in Fragile Landscapes" from May 27-30, 2009 in Beijing, which was funded by NSF China (30910303027), State Key Laboratory of Water Environment Simulation, Lehman Funds of Cornell University, and cosponsored by Higher Education Press, IUCN-China Program, ICRAF-China Program, and TNC-China Program.

This workshop has brought together a group of social, biological, and physical scientists from Beijing Normal University, Cornell University, and elsewhere to examine conservation and sustainable development issues in fragile landscapes worldwide. Totally, we have gathered over 70 participants from over 40 Chinese institutions and 6 international organizations. We have received 56 papers on these topics, and 36 presentations are planned for this workshop. We selected best papers that highlight the updated issues in the fields of coupled human and natural systems to publish them as a special issue for the journal of Frontiers of Earth Science in China. It is within this context that we wish to serve as models because examining coupled human-natural systems worldwide is expected to attract interest from many nongovernment organizations inside and outside China, as well as from numerous

Received October 20, 2009

E-mail: zfyang@bnu.edu.cn 
Chinese governmental agencies. We also expect to foster and support a meaningful working relationship between Chinese scientists and overseas scholars in the related fields through an academic exchange platform for building effective and collaborative partnerships.

We acknowledge the project from the National Natural Science Foundation of China (Grant No. 50939001) for supporting the publication of this special issue.

Prof. Zhifeng Yang, Co-Chair of the Workshop

Prof. Shikui Dong, the General Secretary of the Workshop 